\title{
Associação de Surdos de São Paulo e a defesa pelos direitos linguísticos dos surdos
}

The Deaf Association of São Paulo and the defense of the linguistic rights of the Deaf

La Asociación de Sordos de São Paulo y la defensa de los derechos lingüísticos de los sordos

Natalia Francisca Frazão

Mestra pela Universidade de São Paulo, São Paulo, Brasil.

natalia.ffrazao@gmail.com

ORCID - https://orcid.org/0000-0003-3844-7775

\section{Ana Claudia Balieiro Lodi}

Professora associada na Universidade de São Paulo, São Paulo, Brasil.

analodi@ffclrp.usp.br

ORCID - https://orcid.org/0000-0002-7106-172X

Recebido em 30 de maio de 2019

Aprovado em 7 de agosto de 2019

Publicado em 22 de outubro de 2019

\section{RESUMO}

Este artigo tem como objetivo apresentar o processo histórico das ações coletivas empreendidas pela Associação de Surdos de São Paulo (ASSP), com vistas ao reconhecimento dos direitos linguísticos dos surdos brasileiros em todas as esferas de atividade humana. Para a construção desta pesquisa documental foram utilizados documentos institucionais disponibilizados por seus dirigentes para o desenvolvimento deste estudo, artigos científicos, dissertações de mestrado, teses de doutorado e vídeos disponíveis na internet sobre ações coletivas de surdos. Observou-se que, desde sua fundação, a ASSP em interação contínua com outros atores sociais, contribuiu, de forma significativa, para a luta pelo reconhecimento linguístico dos surdos: propiciou o fortalecimento de uma identidade coletiva e a formação política de muitos surdos; apoiou outras ações coletivas, como a criação de novas associações de surdos e a fundação da Confederação Brasileira de Desportos de Surdos e da Federação Nacional de Educação e Integração dos Surdos; bem como participou, como uma das protagonistas, dos movimentos surdos em prol do reconhecimento da língua brasileira de sinais e da defesa pela educação bilíngue para surdos.

Palavras-chave: Movimentos sociais; Política linguística; Surdo. 
http://dx.doi.org/10.5902/1984686X38332

\section{ABSTRACT}

The objective of this article is to present a historical view of the collective actions carried out by the Deaf Association of São Paulo (ASSP), aimed at recognition of the linguistic rights of Brazilian Deaf people in all spheres of human activity. To carry out this documentary research, the following sources were used: institutional documents, scientific articles, master's theses, doctoral theses, and videos on collective actions carried out by the Deaf. It was observed that, since its foundation, the ASSP, in constant interaction with other social actors, made important contributions in the struggle for the linguistic recognition of the deaf: it fostered the strengthening of a collective identity and the political education of many deaf people; supported collective actions, such as the creation of new Deaf Associations and the founding of the Brazilian Confederation of Sports for the Deaf and the National Federation of Education and Integration of the Deaf; and, likewise, it participated, as one of the protagonists of the Deaf movements in favor of the recognition of the Brazilian sign language and of the defense of bilingual education for the Deaf.

Keywords: Social movements; Language politic; Deaf.

\section{RESUMEN}

Los estudios indican que los estudiantes sordos han presentado un bajo rendimiento en la escuela debido a dificultades en la lectura y la escritura. Esta situación se debe, en parte, a los enfoques utilizados en la enseñanza del portugués como primera lengua, sin ninguna adaptación metodológica. Bajo los supuestos de la educación inclusiva, se espera que el maestro desarrolle adaptaciones curriculares para construir un proceso significativo de enseñanza-aprendizaje. Dado este contexto, este estudio tuvo como objetivo investigar si las adaptaciones curriculares se han implementado en escuelas ordinarias que tienen alumnos sordos inscritos, y también si favorecen el desarrollo de algún tipo de práctica de literacia bilingüe. Apoyado por la Teoría sociohistórico-cultural de Vygotsky (1924-1934) y la política nacional de enseñanza-aprendizaje, este estudio también se basa en la metodología de investigación crítica colaborativa (PCCol) (Magalhães, 2011). Los datos se produjeron mediante la observación de clases de portugués, en salas en las que se inscribieron estudiantes sordos, y también se realizaron entrevistas y sesiones de reflexión. Los resultados indican la ausencia de adaptaciones curriculares debido a la poca capacitación ofrecida a los maestros e indican que la colaboración entre los participantes (investigador e investigado) favorece su implementación, así como el desarrollo de prácticas de literacia bilingües.

Palabras clave: Movimientos sociales; Literacia política; Sordo. 


\section{Introdução}

A Associação de Surdos de São Paulo (ASSP), primeira associação organizada apenas por surdos no Brasil (RANGEL, 2004; FRAZÃO, 2017), referência para a criação de tantas outras em nosso país, teve, desde seu início, participação significativa na luta pela garantia dos direitos linguísticos dos surdos brasileiros em todas as esferas de atividade humana. Entretanto, apesar de sua importância histórica para as comunidades surdas brasileiras, pouco se sabia sobre as ações empreendidas por seus membros e/ou sobre sua participação em movimentos organizados por outras entidades constituídas por este grupo social.

Visando compreender como surgiram as ações coletivas desta instituição e como elas se mantiveram desde sua criação até o ano de 2011, quando foram implementadas as Escolas Municipais de Educação Bilíngue para Surdos na capital paulista, foi realizada uma pesquisa documental de cunho qualitativo, construída a partir de artigos científicos, dissertações de mestrado, teses de doutorado, vídeos disponíveis na internet que discutiam algumas ações coletivas de surdos e documentos da ASSP, disponibilizados por seus dirigentes à pesquisadora especialmente para o desenvolvimento deste estudo. O presente artigo é um recorte desta pesquisa maior e tem como objetivo descrever e analisar as ações coletivas da ASSP no que diz respeito à luta e defesa pelos direitos linguísticos dos surdos.

\section{A fundação da ASSP e sua vinculação com o esporte}

Fundada no ano de 1954 e motivada pela prática esportiva, em especial, o futebol, a Associação de Surdos de São Paulo - ASSP, por um longo período, tornou-se a "casa dos surdos" (FRAZÃO, 2017, p.77): um espaço para o encontro de surdos de diferentes grupos sociais e de distintas gerações, para a elaboração de projetos sociais, para o lazer e para impulsionar a prática esportiva entre surdos e destes com ouvintes. Antes de sua fundação, era comum os surdos se encontrarem em espaços públicos após o período escolar (RANGEL, 2004), locais nos quais podiam se comunicar e conversar sobre diferentes temas por meio da língua de sinais, de gestos ou até mesmo da oralidade, sem haver a imposição de uma única forma de dizer.

Tal afirmação se sustenta ao se considerar que, naquele período histórico, as escolas de surdos existentes no país eram, sem exceção, oralistas, e tinham, por este motivo, como objetivo primeiro, o treinamento auditivo e de fala dos alunos a fim de integrá-los à 
sociedade, impondo uma forma de comunicação comum entre surdos e ouvintes. Visavase assim, por meio da oralidade, igualar surdos e ouvintes linguística e culturalmente, razão pela qual não era permitido aos surdos o uso da língua de sinais, tida como prejudicial tanto para a aprendizagem da linguagem oral da língua portuguesa quanto para a escolar (MOURA, 2000; MOURA; LODI; HARRISON, 2005).

Nesse contexto, um espaço como a ASSP constituía-se em uma oportunidade para que os surdos pudessem se encontrar, compartilhar experiências, conhecimentos e vivências. Mas não apenas isso. A fim de auxiliar na manutenção financeira daquela instituição que abrigava um espaço social e cultural singular, eventos abertos à comunidade eram organizados e, em função destes momentos, ouvintes que nunca haviam interagido com surdos e que não conheciam Libras passaram também a frequentar a ASSP, fato que determinou que novas formas de conceber os surdos e sua língua fossem sendo construídas socialmente.

Entende-se assim que a ASSP, ao propiciar a partilha de "perspectivas de mundo sob o olhar dos próprios surdos" (FRAZÃO, 2017, p.72), tornou-se um espaço de educação não formal (GOHN, 2010) para surdos e para aqueles ouvintes que, pela primeira vez, interagiam com eles. Aos surdos, possibilitou a construção de aprendizagens pelas histórias ímpares que circulavam naquele espaço, criado, inicialmente, para fins esportivos, e pelo convívio de pessoas de diferentes horizontes sociais e de distintas gerações. Aos ouvintes, permitiu a possibilidade de transformação na forma de se conceber e compreender os surdos: de deficientes a pessoas que possuíam uma forma particular de comunicação.

No entanto, o futebol continuava sendo muito importante para ASSP e, nas duas décadas seguintes à sua fundação, o motivo para que nova ação coletiva fosse iniciada por seus membros e dirigentes. Com a abertura de novas associações de surdos pelo país, que contaram com o apoio e a expertise dos dirigentes da ASSP, e com o aumento no número de surdos que passaram a frequentar esses espaços extraescolares, avaliou-se que, apesar do contexto pouco propício que passava o país devido à ditadura militar, seria importante a criação de uma Confederação Brasileira de Desportos de Surdos (CBDS), a fim de ser possível a integração de atletas surdos de diferentes estados brasileiros. Esta ação acabou envolvendo outras e, após mais de uma década, o Conselho Nacional de Desportos aprovou a CBDS. 


\section{Ações da ASSP para além do esporte: a luta pelos direitos linguísticos dos surdos}

Ao mesmo tempo em que os dirigentes da ASSP em parceria com os das Federações Desportivas de Surdos de São Paulo, Rio de Janeiro e Minas Gerais e de outras associações de surdos existentes no país lutavam pela criação da CBDS, outro movimento teve início a partir da segunda metade da década de 1970, liderado, por sua vez, por ouvintes: a criação da Federação Nacional de Educação e Integração do Deficiente Auditivo - Feneida (BRITO, 2013).

Formada unicamente por ouvintes que não acreditavam que os surdos seriam capazes de discutir e tomar decisões sobre assuntos que os envolvia, a Feneida atuava orientando as escolas sobre a compra de aparelhos de amplificação sonora e estimulando a necessidade de um trabalho de oralização dos surdos. Tal prática estava de acordo com as orientações do Centro Nacional de Educação Especial (Cenesp), criado pelo Ministério da Educação em 1973, que tinha como objetivo "promover em todo o território nacional, a expansão e melhoria do atendimento aos excepcionais" (BRASIL, 1973, Artigo $1^{\circ}$ ). Todo o trabalho do Cenesp era pensado a partir da perspectiva médico-pedagógica, por meio da qual a "deficiência" tornava-se o centro da atenção e o foco a ser "tratado"; nesse sentido, "no caso dos surdos, a perda de audição e as 'dificuldades de fala' sobressaiam-se em detrimento do conhecimento escolar" (FRAZÃO, 2017, p.93).

Era necessário, portanto, assumir um posicionamento contrário à ideologia de normalização, agora também imposta pela Feneida. Isso ocorreu na década seguinte, impulsionado, principalmente, pelo fato da Organização das Nações Unidas (ONU) ter considerado o ano de 1981, o Ano Internacional das Pessoas Deficientes, visando, com isso, assegurar às pessoas deficientes plena participação social e em igualdade de condições que as pessoas não deficientes. Segundo Brito (2013, p.89), "as diversas ações previstas implicaram a mobilização de programas e agências especializadas da ONU que passaram a investir recursos e expertise no delineamento, financiamento e realização de vários projetos e eventos". O objetivo era chamar a atenção dos governos e da sociedade civil para a importância de se reconhecer o direito das pessoas deficientes.

Aqui no Brasil, os movimentos das pessoas deficientes foram significativos, e por seu intermédio houve o incentivo e a conscientização dos próprios grupos quanto à necessidade de participar e organizar ações coletivas que assegurassem seus direitos, e de assumir um 
http://dx.doi.org/10.5902/1984686X38332

novo posicionamento político-ideológico com vistas a transformar a forma pela qual eles foram, historicamente, olhados e concebidos: como "objeto de pena, devido à tragédia pessoal que [os] acometera", visão esta que os reduzia "à condição de paciente que precisava ser diagnosticado e tratado para ser curado ou reabilitado" (BRITO, 2013, p.95). Foi o momento no qual os diferentes grupos puderam se autodefinir pessoas diferentes e reivindicar os mesmos direitos de qualquer cidadão brasileiro.

Novas organizações foram criadas e três Encontros Nacionais das Pessoas Deficientes promovidos. Já no primeiro, no ano de 1980, os poucos surdos presentes reivindicaram, pela primeira vez, o uso da linguagem mímica nos espaços escolares, em função das dificuldades que enfrentavam como decorrência da imposição da oralização. No ano de 1981, no segundo Encontro, os surdos reivindicaram novamente a necessidade de uso da linguagem mímica, alegando sua importância como "meio de garantir, às pessoas surdas não oralizadas, o acesso à informação, à educação e ao atendimento nas instituições públicas e privadas" (BRITO, 2013, p.104).

Observa-se, no entanto, que o uso da língua de sinais (então chamada de linguagem mímica) era pensado, quase que exclusivamente, para aqueles surdos que não utilizavam a linguagem oral; nesse sentido, não se compreendeu ter havido uma oposição marcada dos representantes surdos contra o discurso dominante de que eles deveriam ser "normalizados", transformando-se em ouvintes usuários do português oral (FRAZÃO, 2017, p.96).

Em 1983, no terceiro Encontro, foram realizadas algumas propostas organizadoras dos movimentos. Os surdos presentes, agora em maior número, posicionaram-se contrários à proposta de se pensar uma única organização nacional a todos os grupos sociais de pessoas deficientes, mas votaram a favor daquela que defendia a criação de "federações nacionais por tipo de deficiência" (BRITO, 2013, p. 108). Conforme discutiu o autor, especialmente neste terceiro encontro, houve a presença de surdos que, por estarem envolvidos na diretoria das Federações Desportivas e das Associações de Surdos, protagonizavam outros movimentos e ações coletivas em prol do reconhecimento da língua de sinais e de seu uso nos espaços escolares. Lutavam assim pela igualdade de direitos dos surdos como cidadãos brasileiros. Foi neste contexto que se estabeleceu um conflito direto com a Feneida, instituição que, além de não representar os surdos, passava por diversos problemas financeiros. 
http://dx.doi.org/10.5902/1984686X38332

Três importantes movimentos surdos começaram, então, a ser delineados no mesmo período da história, tendo como protagonistas sujeitos que participavam da e/ou mantinham relação direta com a ASSP: a) a luta pelo reconhecimento da língua de sinais nos espaços escolares, pois se assistia a um novo e também negativo momento na educação de seus pares com a adoção da Comunicação Total; b) a oposição à Feneida, por meio da organização de nova ação coletiva que permitiu que, em 1986, os surdos assumissem a instituição, mostrando que eram perfeitamente capazes de gerir assuntos de seu próprio interesse (neste contexto a Feneida passou a ser denominada Federação Nacional de Educação e Integração dos Surdos - Feneis); e c) a continuidade na luta pelo reconhecimento da CBDS pelo Conselho Nacional de Desporto, fato que veio a ocorrer em 1984, graças ao trabalho de todos como equipe:

Os surdos se mantiveram solidários a fim de ser possível a fundação e o
desenvolvimento da instituição e, no decorrer deste processo, mostravam-se
cada vez mais unidos aproveitando as diferentes oportunidades que surgiam
para aprender e compartilhar experiências, independente das diferenças
educacionais e geracionais. Pode-se dizer, portanto, que os anos que se
passaram até a fundação da CBDS, constituiu-se em uma ação coletiva que
determinou o fortalecimento de uma identidade coletiva surda que influenciou,
de forma significativa, as relações sociais na vida cotidiana da Confederação
(FRAZÃO, 2017, p.99).

Destaca-se que em todo este processo, a ASSP teve papel significativo na formação de novos atores sociais, seja por meio de seu apoio e colaboração, seja no compartilhar de uma experiência acumulada há trinta anos. Possibilitou, portanto, como espaço de formação política, a construção partilhada de conhecimentos/aprendizagens de muitos surdos de São Paulo e de diferentes estados. Compreende-se, nesse sentido, a colocação de Abreu (2016), quando o autor destaca a participação de alguns atores que lutaram junto à ASSP para o reconhecimento da CBDS e que acabaram deixando a instituição para participar de novas ações coletivas: atuar e/ou criar novas Associações de Surdos, assumir a presidência da Feneis (RJ) e, posteriormente, compor suas diretorias regionais, como ocorreu no estado de São Paulo na década seguinte.

Ainda no ano de 1987 na cidade de São Paulo, a ASSP, em parceria com pais, professores e Sociedades de Amigos de Bairro, protagonizou nova ação coletiva: a criação de escolas especiais para surdos nas diferentes regiões de São Paulo. A Câmara Municipal, no ano de 1988, aprovou o pedido e São Paulo recebeu quatro novas escolas públicas de educação infantil e de ensino de primeiro grau (como era chamado o que conhecemos hoje 
por anos iniciais do ensino fundamental), especialmente criadas para os alunos surdos. Elas foram chamadas de Escolas Municipais de Educação dos Deficientes Auditivos Emedas e localizavam-se nas quatro regiões da cidade - norte, sul, leste e oeste.

No final da década de 1980 e início da de 1990, nessas instituições e em outras escolas para deficientes auditivos existentes na capital paulista, intensificava-se o uso da comunicação bimodal em "substituição" à perspectiva oralista. No entanto, fora das salas de aulas, estudantes e adultos surdos, assim como no passado, continuavam a comunicarse livremente, em uma interação na qual as diferenças sociais e educacionais não importavam. Neste mesmo período, segundo Brito (2013), em função da relação que foi se estabelecendo entre surdos e pesquisadores de universidades públicas e privadas do pais, a língua brasileira de sinais (Libras) começou a ser estudada e foi reconhecida pela academia como língua (por este motivo deixou de ser chamada de linguagem mímica) e seu uso nos espaços escolares defendido.

Com o uso cada vez mais frequente da Libras fora dos muros da escola e de forma informal em seu interior, com as lutas pelo seu reconhecimento e para sua aceitação nos espaços escolares, os membros da ASSP passaram também a se preocupar com a educação: a reivindicação agora era a transformação das escolas especiais para deficientes auditivos em escolas bilíngues para surdos.

Foi nesse contexto que, em 1997, a ASSP reformulou seu estatuto tornando-se de "caráter beneficente, cultural, educativa, desportiva, recreativa, [e] social" (FRAZÃO, 2017, p.109). Neste novo estatuto, percebe-se a preocupação com diferentes aspectos que envolvem a vida dos surdos e, além daqueles já presentes no documento que constituiu a ASSP - assegurar espaços de caráter desportivo, recreativo e social - a instituição comprometeu-se em atuar e garantir, a partir daquele momento, ações envolvendo questões relativas à cultura e à educação dos surdos. Para isso, a ASSP passou a defender um maior comprometimento de seus membros tanto com a associação quanto com o uso e divulgação da Libras.

No ano de 1997, a Feneis, que tem como objetivos defender "políticas linguísticas, educação, cultura, saúde e assistência social para a Comunidade Surda, assim como seus direitos" (FENEIS, s/d, s/p), abriu uma diretoria regional em São Paulo. Seus membros diretores e associados, que já haviam lutado junto a ASSP para a criação da CBDS, podiam, novamente, somar esforços a fim de fortalecer as lutas que esta associação vinha liderando 
http://dx.doi.org/10.5902/1984686X38332

até aquele momento na cidade de São Paulo. E juntando suas "vozes" às dos demais surdos de outras instituições, como, por exemplo, a Feneis Rio de Janeiro e diferentes associações de surdos que lideravam ações em outros estados, passaram a pressionar o governo federal para o reconhecimento da Libras como a língua por meio da qual os surdos enunciam. Esta luta, no entanto, seguia sem êxito.

Dois anos mais tarde, em 1999, foi realizado um evento que foi considerado por muitos, "peça fundamental da campanha pela oficialização da Libras" (BRITO, 2013, p.192): o V Congresso Latino-Americano de Educação Bilíngue para Surdos, organizado pelo Núcleo de Pesquisas em Políticas Educacionais para Surdos da Universidade Federal do Rio Grande do Sul, e que contou com a parceria da Feneis (e suas regionais). Nesse evento, os surdos protagonizaram discussões, debateram questões sociais e educacionais que os envolvia e elaboraram um documento "A educação que nós surdos queremos", por meio do qual se percebe o quanto os surdos, no decorrer do período aqui discutido, foram, gradativamente, ganhando articulação política em sua luta no que diz respeito aos seus direitos linguístico. Por meio dele, puderam ainda se opor, de forma explícita, à política educacional brasileira que dava seus primeiros passos rumo a implantação da educação inclusiva no país.

Compreende-se, neste movimento que, pela primeira vez, as ações dos surdos voltaram-se para o rompimento com os sistemas sociais hegemônicos, dando, à sua luta, visibilidade nacional; uma prática política que, pode-se dizer, nascia com a organização dos surdos para a fundação da ASSP, que esteve presente, de forma direta ou indireta, nas diversas outras ações ocorridas no país (FRAZÃO, 2017, p.111)

Poucas mudanças ocorreram nos anos seguintes, embora a ASSP e a Feneis continuassem, juntamente com as comunidades escolares de surdos, a pressionar os Poderes Públicos quanto à necessidade de reconhecimento da Libras e a aceitação de seu uso nos espaços escolares. Para isso, realizavam e participavam de eventos nos quais estas reivindicações eram frequentemente tematizadas. Destaca-se, neste contexto, a realização da I Conferência dos Direitos e Cidadania dos Surdos do Estado de São Paulo (Condicisur), no ano de 2001, na cidade de São Paulo. Para Brito (2013, p. 200), o evento "teve um cunho essencialmente político, na medida em que o seu principal objetivo era discutir e elaborar propostas que atendessem as reivindicações trazidas pelos representantes das comunidades surdas da capital e do interior de São Paulo". 
http://dx.doi.org/10.5902/1984686X38332

Neste evento foram ainda propostas estratégias políticas de luta, pois era necessário "obter a aprovação de leis municipais e estaduais de reconhecimento da Libras, sem, com isso, perder o foco da reivindicação da oficialização dessa língua em âmbito nacional" (BRITO, 2013, p. 201). A proposta tirada na Condicisur foi, enfim, aprovada e o reconhecimento da Libras no município de São Paulo ocorreu por meio da Lei Municipal no 13.304, sancionada pela prefeita Marta Suplicy, em 2002. Por meio desta lei, "fica reconhecida oficialmente, no Município de São Paulo, a Língua Brasileira de Sinais LIBRAS, e outros recursos de expressão a ela associados, como língua de instrução e meio de comunicação objetiva e de uso corrente da comunidade surda" (SÃO PAULO, 2002, Artigo 1ㅇ).

Apesar do inegável valor desta lei para os surdos paulistanos, observa-se que, em um primeiro momento, o reconhecimento sobre a necessidade de uso desta língua reduzia-se à rede pública municipal de ensino e às instituições que atendiam o aluno surdo (SÃO PAULO, 2002, Artigo 5) e, mesmo nesses espaços, percebe-se ainda a ideia equivocada de que apenas o uso da língua seria suficiente para assegurar a educação bilíngue. Negase assim, que este modelo educacional, além da centralidade da Libras, implica na necessidade de se rever metodologias/práticas de ensino, que devem ser construídas a partir da Libras, ao invés de haver a tradução daquelas pensadas em português para a língua de sinais. Soma-se a isso a necessidade de complementação curricular, envolvendo a inclusão de temas relacionados aos aspectos socioculturais e históricos das comunidades surdas, não contemplado em nenhuma legislação até os dias de hoje.

Três meses após a publicação da Lei Municipal em São Paulo, foi sancionada a Lei Federal que reconheceu a língua brasileira de sinais como "meio legal de comunicação e expressão" (BRASIL, 2002, Artigo $1^{\circ}$ ) das comunidades surdas brasileiras - lei $\mathrm{n}^{\circ}$ 10.436/02. Por seu intermédio, mesmo que a Libras não tenha adquirido caráter oficial, ela passou a ser reconhecida pelo menos nas esferas jurídicas; no entanto, para que esse reconhecimento abrangesse também a sociedade em geral, era preciso que as associações, os líderes dos movimentos e as comunidades escolares de surdos se mantivessem unidos e passassem a trabalhar na divulgação da lei e da língua a fim de que houvesse o respeito aos direitos linguísticos dessas comunidades.

Com a promessa de superar as desigualdades sociais e educacionais que ainda persistiam no país, Luiz Inácio Lula da Silva assumiu a presidência da República e, uma 
das marcas de seu governo, foi o investimento na educação básica e superior. No que diz respeito à educação de surdos, sancionou o Decreto Federal no 5.626, no ano de 2005, que assegurou aos surdos a educação bilíngue. No entanto, apesar desta ação afirmativa em relação às comunidades surdas brasileiras, três anos após a publicação do Decreto no 5.626/05, a Política Nacional da Educação Especial na Perspectiva da Educação Inclusiva foi publicada pelo mesmo Governo Federal, e por meio desta Política, a inclusão dos surdos nas escolas regulares, em salas pensadas e organizadas para alunos ouvintes, passou a ser defendida.

Observa-se assim uma grande contradição nos documentos oficiais brasileiros, pois enquanto no Decreto no 5.626/05 a Libras tem papel central para a educação dos surdos, na Política de Educação Especial a orientação é a matrícula dos surdos em salas em que a língua de interlocução professor - alunos e entre alunos é a língua portuguesa. A Libras, presente em sala de aula por meio de tradutores e intérpretes, ganha caráter instrumental, distanciando-se, desse modo, de seu status linguístico. Conforme discutiu LODI (2013), em um movimento muito próximo ao ocorrido em décadas anteriores, a inclusão, da forma como defendida pela Política de Educação Especial, nega as

\footnotetext{
línguas de sinais de forma velada, permitindo e, discursivamente, aceitando sua presença, ao mesmo tempo em que, na prática, elas eram [/são] descaracterizadas e assimiladas pela gramática da língua majoritária (LODI, 2005). Dessa forma, a língua de sinais era [/é] submetida a compartilhar, com a linguagem oral, os mesmos espaços discursivos, e os sinais eram [/são] tratados como instrumento para o desenvolvimento daquela língua (p.56).
}

Com a publicação da Política, o Estado brasileiro começou a não medir esforços para concretizar seu projeto de educação, cujo "imperativo central e único das políticas públicas em Educação Especial" (RESENDE; LACERDA, 2013, p. 412) passou a ser a inserção de todos os estudantes na mesma escola e na mesma sala de aula. O último movimento nesta direção em relação aos surdos foi a ameaça, realizada no ano de 2011, pela então Diretora de Políticas de Educação Especial do Ministério da Educação. Segundo a Diretora, até o final daquele ano, o Instituto Nacional de Educação de Surdos (Ines) seria fechado e, assim como já em andamento em outras instituições específicas de surdos, os alunos seriam transferidos para as escolas comuns (CAMPELLO; REZENDE, 2014). Este fato foi determinante para que novas ações fossem empreendidas pelos surdos brasileiros, que se mobilizavam agora pelo reconhecimento dos seus direitos de uso da Libras nos espaços escolares, impossível de ocorrer por meio da educação inclusiva da forma como 
http://dx.doi.org/10.5902/1984686X38332

compreendida pela Política de Educação Especial. Com isso, a ASSP em parceria com a Feneis e com apoio das comunidades das escolas de surdos da cidade de São Paulo organizou uma manifestação pública na Avenida Paulista no ano de 2009.

\begin{abstract}
Mais uma vez, uma mobilização política teria por palco esse famoso cartão postal da cidade de São Paulo. O número de participantes era relativamente tímido, se comparado a outras manifestações que costumam ocorrer no local, contudo, suficiente para tomar toda a calçada do Parque Trianon. Quem observava mais atentamente, percebia algumas particularidades na forma de comunicação das pessoas que se aglomeravam. Os manifestantes se comunicavam por meio de língua de sinais e, apesar de haver um carro de som no local, o foco de atenção estava voltado sobretudo para as pessoas que discursavam em língua de sinais, em pé, sobre as lixeiras de concreto da avenida, que serviam como palanques improvisados, a fim de tornar visíveis os seus sinais para os demais. Aquela concentração, aos poucos, demonstrava o seu objetivo em tomar parte da avenida: tratava-se de uma manifestação pelos direitos do que as pessoas denominam comunidade surda. Quando alguns surdos, representantes de associações, discursavam, o carro de som propagava a interpretação para o português realizada por um interprete. Inversamente, quando alguns ouvintes discursavam, o interprete presente ocupava o palanque improvisado interpretando o dito para Libras (SILVA et al., 2009, p. 1-2).
\end{abstract}

Esta ação coletiva desenvolvida em São Paulo inseriu-se, segundo FRAZÃO (2017), em uma rede maior de movimento, por meio da qual houve a participação de vários atores coletivos que lutavam por um interesse comum: a defesa pelas escolas de educação bilíngue para surdo e, portanto, pelos direitos linguísticos dos surdos.

Pode-se dizer ainda que por meio desta ação, os surdos paulistanos demonstraram que, no decorrer da história, houve a construção de uma consciência coletiva, um amadurecimento em suas formas e estratégias de luta e, portanto, aprendizagens determinadas socialmente. Entende-se que o processo aqui apresentado contribuiu para a formação cidadã, do "indivíduo para a vida e suas adversidades"; para o desenvolvimento de "uma cultura política do grupo" e, portanto, para a constituição de "um sentimento de identidade com uma determinada comunidade"; para a "construção e (re)construção de concepções de mundo e sobre o mundo" (GOHN, 2010, p.21). Conhecimentos, portanto, que foram sendo construídos na convivência com aqueles que compõem o grupo de pertencimento.

Na capital paulista, no ano de 2010, novo movimento, organizado pela ASSP e pela Feneis - SP foi realizado, tendo como pauta "a manutenção e a reestruturação das escolas de surdos já existentes na cidade; a garantia de presença de professores surdos nas escolas e de profissional intérprete e guia-intérprete para os surdo-cegos; e a criação de 
http://dx.doi.org/10.5902/1984686X38332

cargos de instrutor surdo" (DE OLHO NO PLANO SÃO PAULO, 2010). No ano de 2011, houve nova mobilização em defesa das escolas bilíngues pelos surdos de São Paulo, que, uma vez mais, contou com o apoio da ASSP - Caminhada do dia do Surdo - e dois meses depois, o VI Festival Esportivo e Cultural de Alunos Surdos (SILVA; ASSÊNCIO, 2011), quando foi assinado o Decreto Municipal no 52.785/11 que, além de garantir a permanência das escolas de surdos na cidade, alterou o nome das mesmas para Escolas Municipais de Educação Bilíngue para Surdos - Emebs (SÃO PAULO, 2011).

Observa-se, dessa maneira, que as ações coletivas dos surdos da ASSP iniciadas na década de 1950, e que tinham com foco o esporte, foram gradativamente se alterando, em um movimento de luta contínua que visou assegurar o respeito aos direitos linguísticos dos surdos. Nesse processo, a identidade coletiva dos surdos que enunciam em Libras pode ser fortalecida, bem como houve a construção de uma capacidade de agir coletivo, determinando "mudanças sociais nas relações tanto entre atores coletivos dentro da ação coletiva quanto destes com os sistemas sociais" (FRAZÃO, 2017, p.127).

\section{Considerações finais}

Observa-se que no decorrer de quase seis décadas, as diferentes ações coletivas desenvolvidas pelos surdos sempre tiveram apoio e participação ativa de líderes e membros da ASSP - primeira Associação de Surdos fundada em nosso país. Em 1954, quando de sua fundação, a língua de sinais e o direito ao seu uso nas diferentes esferas de atividade humana não era foco de atenção; o que unia os surdos que dirigiam e que se associavam à ASSP era o reconhecimento da importância de se ter um espaço físico para encontros, o desenvolvimento de projetos sociais e de atividades de lazer e esportivas. Tornou-se, assim, a "casa dos surdos" e nela o uso da língua de sinais e/ou da linguagem oral da língua portuguesa, imposta nos espaços escolares, eram aceitas. No decorrer do convívio diário e no compartilhar experiências de pessoas de diferentes vivências sociais e de distintas gerações, um vínculo social foi constituído, assim como um forte sentimento de pertencimento àquele espaço.

Esta experiência foi fundamental para que outras associações de surdos em outras cidades do estado de São Paulo e em outros estados fossem criadas com o apoio e orientação dos fundadores e membros da ASSP. Pode-se dizer assim, que a ASSP iniciou a construção de redes de relações formais e/ou informais entre diferentes atores coletivos 
http://dx.doi.org/10.5902/1984686X38332

surdos, que foram se ampliando no decorrer do tempo e que levaram a novas ações coletivas, "ao se considerar, conforme discutiu Melucci (2001), que nenhum movimento surge sozinho ou por acaso" (FRAZÃO, 2017, p.130).

As novas ações que surgiram após a fundação da ASSP podem ser compreendidas como movimentos surdos que foram sendo (re)criados em função dos novos contextos socioculturais que vivenciavam no decorrer da história e de objetivos comuns que se transformavam e se renovavam. Neste contexto, a ASSP, mais que um local de convivência e de práticas de esportes, tornou-se um espaço no qual os surdos assumiram protagonismos em decisões que os envolvia e no qual "a língua de sinais figurasse como fundante de uma identidade coletiva surda" (FRAZÃO, 2017, p.131).

Nesse contexto, compreende-se que as experiências construídas coletivamente e acumuladas no decorrer dos anos pelos membros da ASSP e sua influência e participação em novos movimentos sociais, constituiu-se em processos de aprendizagem para a formação de novos atores sociais e para a projeção de futuras ações coletivas, como por exemplo, os movimentos de reconhecimento da Libras.

Pode-se dizer, portanto, que a fundação da ASSP pode ser comparada com uma árvore, que cresceu, se fortaleceu e amadureceu; seus galhos geraram flores - a fundação de outras associações e da CBDS - e frutos - novos movimentos sociais, que se concretizaram posteriormente: a fundação da Feneis e o reconhecimento da língua de sinais e da importância da educação bilíngue para surdos (FRAZÃO, 2017, p.100).

\section{Referências}

ABREU, Antônio. História - Esporte dos Surdos e líderes Surdos CBDS. 16 ago. 2016f. Disponível em: https://www.youtube.com/watch?v=_C0ABUU31Qs\&t=122s. Acesso em: 11 abr.2017.

BRASIL. Decreto n. 72.425, de 3 de julho de 1973. Cria o Centro Nacional de Educação Especial (CENESP), e dá outras providências. Disponível em: http://www2.camara.leg.br/legin/fed/decret/1970-1979/decreto-72425-3-julho-1973420888-publicacaooriginal-1-pe.html. Acesso em: 30 jun.2017.BRASIL. Lei n. 10.436, de 24 de abril de 2002. Dispõe sobre a Língua Brasileira de Sinais - Libras e dá outras providências. Disponível em: http://www.planalto.gov.br/ccivil_03/leis/2002//10436.htm. Acesso em: 10 mai. 2018. 
http://dx.doi.org/10.5902/1984686X38332

BRASIL. Decreto n. 5.626, de 22 de dezembro de 2005. Regulamenta a Lei no 10.436 , de 24 de abril de 2002, que dispõe sobre a Língua Brasileira de Sinais - Libras, e o art. 18 da Lei $n^{\circ} 10.098$, de 19 de dezembro de 2000. Disponível em:

http://www.planalto.gov.br/ccivil_03/_ato2004-2006/2005/decreto/d5626.htm. Acesso em: 9 mai.2018.

BRASIL. Política Nacional de Educação Especial na Perspectiva da Educação Inclusiva. Brasília: MEC/SEESP, 2008. Disponível em:

http://portal.mec.gov.br/arquivos/pdf/politicaeducespecial.pdf. Acesso em: 10 mai. 2018.

BRITO, Fábio Bezerra de. O movimento social surdo e a campanha pela oficialização da língua brasileira de sinais. 2013. 275f. Tese (Doutorado em Educação), Faculdade de Educação da Universidade de São Paulo, São Paulo. Disponível em: http://www.teses.usp.br/teses/disponiveis/48/48134/tde-03122013-133156/pt-br.php. Acesso em: 17 mai. 2018.

CAMPELLO, Ana Regina; REZENDE, Patrícia Luiza Ferreira. Em defesa da escola bilíngue para surdos: a história de lutas do movimento surdo brasileiro. Educar em Revista, Curitiba, Brasil, Edição Especial n. 2/2014, p. 71-92. Editora UFPR. Disponível em: http://www.scielo.br/pdf/er/nspe-2/06.pdf. Acesso em: 19 jul. 2019.

DE OLHO NO PLANO SÃO PAULO. De olho São Paulo. Disponível em: http://www.deolhonoplano.org.br/not0027.html. Acesso em: 15 jul. 2017.

FEDERAÇÃO NACIONAL DE EDUCAÇÃO E INTEGRAÇÃO DOS SURDOS. Feneis. Disponível em: http://www.libras.com.br/feneis. Acesso em: 20 jul.2019.

FRANÇA, Tiago Henrique. A normalidade: uma breve introdução à história social da deficiência. Revista Brasileira de História \& Ciências Sociais, v.6, n.11, p.105-123, julho de 2014. Disponível em: https://www.rbhcs.com/rbhcs/article/view/205/199. Acesso em: 20 jul.2019.

FRAZÃO, Natalia Francisca. Associação de Surdos de São Paulo: identidade coletiva e lutas sociais na cidade de São Paulo. 2017. 141f. Dissertação (Mestrado em Educação), Faculdade de Filosofia, Ciências e Letras de Ribeirão Preto, São Paulo. Disponível em: http://www.teses.usp.br/teses/disponiveis/59/59140/tde-09112017133947/pt-br.php. Acesso em: 07 out.2019.

GOHN, Maria da Glória. Educação não formal e o educador social: atuação no desenvolvimento de projetos sociais. São Paulo: Cortez, 2010.

LODI, Ana Claudia Balieiro. Educação bilíngue para surdos e inclusão segundo a Política Nacional de Educação Especial e o Decreto ํㅜ 5.626/05. Educ. Pesqui., São Paulo, v.39, n.1, p.49-63, jan./mar. 2013.

MELUCCI, Alberto. A invenção do presente: movimentos sociais nas sociedades complexas. Tradução Maria do Carmo Alves Bomfim. Petrópolis, RJ: Vozes, 2001. 
http://dx.doi.org/10.5902/1984686X38332

MOURA, Maria Cecília. O Surdo: Caminhos para uma nova identidade. São Paulo: Revinter, 2000.

MOURA, Maria Cecília; LODI, Ana Claudia B.; HARRISON, Kathryn M.P. História e educação: o surdo, a oralidade e o uso de sinais. In: LOPES FILHO, O. (Ed) Tratado de Fonoaudiologia. $2^{\mathrm{a}}$ ed. Ribeirão Preto: Tecmedd, 2005, p. 341-364.

RANGEL, Gisele Maciel Monteiro. História do povo surdo em Porto Alegre: imagens e sinais de uma trajetória cultural. 2004. 157. Dissertação de mestrado, Universidade Federal do Rio Grande do Sul, Porto Alegre. Disponível em:

http://www.lume.ufrgs.br/bitstream/handle/10183/5148/000510697.pdf. Acesso em: 17 abr. 2017.

RESENDE, Alice Almeida Chaves de; LACERDA, Cristina Broglia Feitosa de.

Mapeamento de Alunos Surdos Matriculados na Rede de Ensino Pública de um Município de Médio Porte do Estado de São Paulo: Dissonâncias. Rev. Bras. Ed. Esp., Marília, v.19, n.3, p. 411-424, Jul.-Set., 2013. Disponível em:

http://www.scielo.br/pdf/rbee/v19n3/08.pdf. Acesso em: 19 jul. 2019.

SÃO PAULO. Lei n. 13.304, de 21 de janeiro de 2002. Reconhece, no âmbito do Município de São Paulo a Língua Brasileira de Sinais, LIBRAS, como língua de instrução e meio de comunicação objetiva e de uso corrente da comunidade surda, e dá outras providências. Disponível em:

https://www.imprensaoficial.com.br/Certificacao/GatewayCertificaPDF.aspx?notarizacaolD =92211e47-291d-42a3-849c-393dc13a8b94. Acesso em : 25 de maio de 2019.

SÃO PAULO. Decreto Municipal no 52.785, de 10 de novembro de 2011. Cria as Escolas Municipais de Educação Bilíngue para Surdos - EMEBS na Rede Municipal de Ensino. Disponível em:

http://www3.prefeitura.sp.gov.br/cadlem/secretarias/negocios_juridicos/cadlem/integra.asp ?alt=11112011D\%20527850000. Acesso em: 19 mai. 2017.

SILVA, César Augusto de Assis; ASSÊNSIO, Cibele Barbalho; SANDES, Leslie Lopes; ALMEIDA, Priscila Alves de. Dia do Surdo na Avenida Paulista: Etnografando a Mobilização Política pelas Escolas Especiais. Ponto Urbe (Online), 5, 2009. Disponível em: http://pontourbe.revues.org/1602. Acesso em: 3 mai. 2018.

SILVA, César Augusto de Assis; ASSÊNSIO, Cibele Barbalho. Setembro Azul: mobilização política nacional a favor das escolas bilíngues para surdos. Ponto Urbe (Online), 9, 2011. Disponível em: http://pontourbe.revues.org/1966. Acesso em: 3 mai. 2018. 
http://dx.doi.org/10.5902/1984686X38332

\section{Notas}

${ }^{1}$ Entende-se por ideologia da normalização a crença de "que, por meio da habilitação e reabilitação, deve-se prover às pessoas com deficiência serviços que ajam sobre seus corpos para que executem funções mais próximas possíveis do normal. Normalidade, nesse caso, traduz-se na execução de ações como fariam na média as pessoas que não têm deficiência" (FRANÇA, 2014, p.111).

2 Filosofia de trabalho, criada nos Estados Unidos na década de 1960, que defendia o uso de distintas formas de comunicação para com a criança surda, visando "fornecer uma comunicação fácil, livre (...) entre a criança surda e o seu ambiente mais próximo" (MOURA; LODI; HARRISON, 2005, p.296), cabendo à criança escolher qual forma ela se adaptava melhor. Na prática, a forma de comunicação usada pelos adeptos da comunicação total ficou conhecida por comunicação bimodal ou bimodalismo, por se usar duas modalidades de linguagem simultaneamente - a oral e a gestual.

\section{Correspondência}

Natalia Francisca Frazão - Universidade de São Paulo, Faculdade de Filosofia Ciência e Letras de Ribeirão Preto, Vila Monte Alegre, Ribeirão Preto, São Paulo - Brasil. CEP: 14040-901.

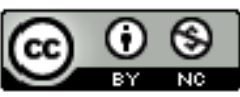

This work is licensed under a Creative Commons Attribution-NonCommercial 4.0 International (CC BY-NC 4.0) 